\title{
O ofidiário e as jararacas: acontecimento midiático, discurso político e deslizamento de sentido
}

\author{
The Portuguese terms ofidiário and jararaca: media event, political discourse and \\ meaning displacement \\ Adelino Pereira dos Santos* \\ Universidade do Estado da Babia, Santo Antônio de Jesus, Bahia, Brasil
}

\begin{abstract}
Resumo: Neste texto, analisamos o termo jararaca e as imagens presentes na capa e na reportagem principal da revista Veja, de 16 de março de 2016, a partir da reflexão sobre acontecimento midiático, discurso político e deslizamento de sentido, tendo como suporte teórico e metodológico a Análise de Discurso de linha francesa. Iniciamos o ensaio com a descrição de um enunciado que foi pronunciado pelo ex-presidente Luís Inácio Lula da Silva, no contexto da Operação Lava Jato, para discutir sobre o embate político, jurídico e midiático que tencionou o Brasil no mês de março de 2016. O que estamos chamando, neste ensaio, de deslizamento de sentido refere-se ao fato de o termo jararaca ser reenunciado e provocar efeitos de sentido contrários ao pretendido pelo ex-presidente Luís Inácio Lula da Silva, retomado em palavras equivalentes ou por outras semioses, sob a égide de outra formação discursiva. Esse processo discursivo demarca bem a luta política que se estabeleceu no país no primeiro semestre de 2016, retomado neste texto pela metáfora do jogo de futebol, conforme pensada por Pêcheux (2002). Courtine (2006, p. 82) destaca o papel da memória no jogo de operações que torna possível a constituição e a dispersão do discurso político: "se o interdiscurso, portanto, organiza a recorrência e o reagrupamento de formulações, igualmente intervém como uma cavidade, ruptura ou deslocamento". Ainda, continua ele (idem), a memória se faz também de esquecimentos porque o interdiscurso "é o produtor do esquecimento dos enunciados. Memória e esquecimento não podem ser dissociados no modo de enunciação do discurso político".
\end{abstract}

Palavras-chave: Enunciado. Acontecimento midiático. Deslizamento de sentido.

\begin{abstract}
In this text, we analyze the Portuguese term jararaca and the images on the cover and in the main article of Veja magazine of March 16 th, 2016 . Based on theoretical and methodological support of French Discourse Analysis, we consider these term and images as part of a media event, containing political discourse and meaning displacement. We start the essay with the analysis of a former Brazilian President Luís Inácio Lula da Silva statement in the context of Lava Jato Operation in order to discuss the political, legal and media tension that occurred in Brazil in March, 2016. Meaning displacement refers to the fact that the Portuguese term jararaca was repeated and caused effects of contrary meaning to what the former president Luís Inácio Lula da Silva desired, taken in equivalent words or in other semiosis, under the aegis of another discursive formation. This discursive process demarcates the political struggle that was established in the country in the first half of 2016, resumed in this text by the metaphor of a soccer game, as thought by Pêcheux (2002). Courtine (2006, p. 82) highlights the role of memory in the gambling operations that enables the creation and dispersal of political discourse: "If the interdiscourse therefore organizes the recurrence and the regrouping of formulations, also acts as a cavity , rupture or displacement." Furthermore, he adds that the memory is also made of forgetfulness because the interdiscourse "is the oblivion of statements producer. Memory and forgetfulness cannot be separated in the enunciation of the political discourse."
\end{abstract}

Keywords: Enunciation. Media event. Meaning displacement.

* Doutor em Letras. Professor adjunto da Universidade do Estado da Bahia. E-mail: adesantos@uneb.br. Apoio: FAPESB-CAPES/ Edital 017/2015. 


\section{O ACONTECIMENTO MIDIÁTICO: A JARARACA}

No dia 04 de março de 2016 a força de um enunciado, no contexto da enunciação, o fez atravessar o país e provocar protestos, aplausos, manifestações de apoio e contestação, tumultos, réplicas e, a partir dele, o surgimento de outros tantos acontecimentos, discursos e textos. Destacado da (entrevista/pronunciação) coletiva de imprensa que o ex-presidente Luís Inácio Lula da Silva deu na sede do diretório do Partido dos Trabalhadores (PT), na região central de São Paulo, o acontecimento político, midiático e discursivo veio à tona precisamente às $15 \mathrm{~h} 11 \mathrm{~min}$., linguisticamente materializado da seguinte forma: "Me senti ultrajado como se fosse um prisioneiro, apesar do tratamento cortês dos delegados da Polícia Federal. Se quiseram matar a jararaca não bateram na cabeşa, acertaram o rabo. E a jararaca está viva como nunca esteve ${ }^{1 "}$. Nesse enunciado, o ex-presidente Lula refere-se ao fato de ele ter sido conduzido coercitivamente, escoltado por agentes fortemente armados, para depor na sede da Polícia Federal (PF) no aeroporto de Congonhas, na manhã daquele dia.

O sentido pretendido pelo enunciador, no trecho em itálico, é o da possibilidade de ele se recandidatar à presidência da república em 2018, e de que haveria a necessidade de o Partido dos Trabalhadores se reerguer, por estar supostamente envolvido nos vários escândalos de corrupção por desvios de verbas, revelado pela Operação Lava Jato, que investiga a malversação de recursos bilionários da Petrobrás, por isso considerado um dos maiores escândalos de corrupção do país. A Lava Jato, comanda pelo juiz Sérgio Fernando Moro, da $13^{\mathrm{a}}$ Vara Federal Criminal de Curitiba/PR, foi ostensivamente iniciada em 17 de março de 2014, e já tem vários políticos, empreiteiros e associados presos, condenados e sob investigação. Afinal, ainda nessa mesma entrevista, o enunciador explicara, um minuto antes, que "Embora estivesse magoado, achava que o que aconteceu hoje era o que precisava acontecer para o PT levantar a cabeça. Há muito tempo o PT estava de cabeça baixa". Lula se tornou o principal alvo da $24^{a}$ fase dessa Operação, porque haveria evidências de que ele recebeu valores desviados do esquema de corrupção da Petrobrás, por meio da destinação e reforma de um apartamento tríplex no Guarujá, na microrregião litorânea de Santos/SP, aquisição e reforma de um sítio em Atibaia, estância hidromineral na região serrana de São Paulo, a aproximados $60 \mathrm{~km}$ de distância da capital, entre outros envolvimentos financeiros e fiscais delituosos associados à empreiteira OAS, uso de nome de terceiros ("laranjas") para ocultação de patrimônio, e outras acusações. Essa fase da Lava Jato foi cognominada de Operação Aletheia, termo utilizado pela Polícia Federal na suposição da "busca da verdade", "desvelamento da verdade suprema".

Recuando-nos um pouco no tempo e no espaço, mas sem nos afastarmos dos fios que nos ligam à história, Michel Pêcheux (2002) analisa a força de um enunciado que, segundo ele, atravessou a França no início dos anos 1980, a partir do anúncio da vitória de François Mitterand à presidência da República Francesa, no dia 10 de maio de 1981. O enunciado "On a gagné" [a gente ganhou/ganhamos] foi pronunciado às 20 horas e poucos minutos e, segundo Pêcheux (2002), ele se

\footnotetext{
${ }^{1}$ Disponível em http://www.opovo.com.br/app/politica/. Acesso em 13/03/2016.
} 
consubstanciara em um acontecimento, como ponto de encontro entre a atualidade do momento e a memória (historicidade/interdiscurso). Pêcheux (2002) apresenta paráfrases para esse enunciado, buscando compreender os possíveis sentidos que justificariam o seu aparecimento, na materialidade linguística do verbo ganhar, enunciado sem a explicitação discursiva do sujeito e nem do complemento.

As questões postas por Pêcheux (2002) são as seguintes: quem realmente, em verdade, ganhou? O posto, o fato, o que é evidente e enunciado pelos meios de comunicação, pelas emissoras de televisão que acompanhavam a apuração das eleições, em clima de suspense pela contagem voto a voto, é que F. Mitterand foi eleito presidente. Mas, quem ganhou, além das aparências? A esquerda francesa? A coalizão socialista-comunista, que se apoderaria da França? O que se ganhou, sentidos outros que sustentariam o dito, quando o enunciado ("on a gagné(ganhamos") foi exaustivamente, alegremente, repetido por cada um dos cidadãos franceses, daqueles que se reuniram em massa na Praça da Bastilha?

Pêcheux (2002) elabora a metáfora de duas equipes de futebol, quando uma delas ganha a partida no fim de um campeonato. Os sentidos que complementam o verbo/enunciado "on a gagné/ganhamos" não são os mesmos para a equipe em si, para os dirigentes do clube de futebol, para os preparadores físicos, para os líderes das torcidas, para cada um dos jogadores ou dos torcedores em particular. De igual sorte, a tensão política que se instalou no Brasil no mês de março de 2016 demarca a atualidade da referência metafórica de Pêcheux: de um lado, como um time em campo, aqueles que se aglutinam figurativamente na formação discursiva dos pró-Lula, em defesa do PT e da governabilidade da então Presidente da República do Brasil, Dilma Rousseff, que materializa/m/vam o enunciado "Não vai ter golpe!", repetido também exaustivamente em diferentes/mesmos contextos de enunciação; e daqueloutros, partidários em contrário e a favor do impeachment da presidente, que enucia/m/vam o "Fora Dilma!". Desse modo, o enunciado "On a gagné/ganhamos" tanto no contexto da partida de futebol ou no cenário político francês do início dos anos 1980 aponta para a polissemia, o emaranhado de sentidos possíveis a complementar o verbo ganhar, repetido à exaustão e ressignificado a cada enunciação, nos alegres gritos dos diferentes partidários, torcedores, enunciadores.

Respeitadas as diferenças que o distanciam no tempo e espaço, o enunciado pronunciado pelo ex-presidente Lula em 04 de março de 2016 "Se quiseram matar a jararaca não bateram na cabeça, acertaram o rabo. E a jararaca está viva como nunca esteve", também passa a ser aqui analisado como um acontecimento, tal qual o enunciado "on a gagné/ganhamos" foi analisado por Pêcheux (2002). Mas, se o enunciado francês aponta, como dito, para a polissemia, o enunciado do ex-presidente brasileiro quis apontar para sentidos únicos. Contudo, diferentes enunciadores, filiados então a também diferentes formações discursivas, destacaram desse enunciado, em uma redução intencional e prenhe de sentidos, apenas o termo jararaca, glosado, parafraseado, parodiado, ironizado, etc. das mais diversas formas e contextos de enunciação.

Nas manifestações organizadas em diversas capitais e grandes cidades do país, por mais de 60 entidades sindicais e de organizações sociais pró-Lula-Dilma-PT e contra o Juiz Sérgio Moro/Operação Lava Jato na sexta-feira, 18 de março de 2016, 
a "jararaca" aparecia, verde ou colorida, em papel celofane, em plástico ou outro material reluzente, em figura esvoaçante, comprida, direcionada ao sabor do vento, como uma pipa-dragão a ameaçar os possíveis adversários. Outros sentidos, contudo, advindos de formação discursiva divergente, serão melhor analisados na seção a seguir, em que refletiremos sobre essa metamorfose do termo/enunciado, reconfigurado na batalha aberta no campo do discurso político e midiático.

\section{O DISCURSO POLÍTICO: O REI DAS SERPENTES}

Courtine (2006, p. 64) afirma que o sujeito político, isto é, aquele que enuncia um discurso nesse campo, está assujeitado a muitas condições de produção e recepção de seu enunciado. Para esse autor $(i d e m)$ o sujeito político condensaria, em um todo complexo, linguagem e ideologia. Seria ele o "lugar" onde os sistemas de conhecimento político se articulariam com a competência linguística, em diferenças, mesclas e combinações em uma determinada conjuntura política. Nesse sentido, refletir sobre o enunciado aqui em análise, bem como na subsequente redução ao termo jararaca, nos leva à necessária conclusão de que em cada enunciação, seja do enunciado completo ou da sua redução - jararaca -, na materialidade linguística do termo ou por qualquer outro material semiótico, não se trata do mesmo sujeito porque em cada ocorrência o enunciado/termo se apresenta filiado a diferentes (divergentes? convergentes?) formações discursivas. São exemplos dessas ocorrências o desenho de uma jararaca em um cartaz de uma manifestação de rua, um boneco inflável, ou uma pipa de papel ou plástico, como a que apareceu nas mãos de manifestantes na cidade de Fortaleza/CE, no dia 18 de maio de 2016, em uma das manifestações/passeatas em defesa de Lula/Dilma/PT e conta a Operação Lava Jato/juiz Sérgio Moro, conforme já mencionamos.

Igualmente, o aparecimento do termo jararaca, conforme se apresenta na capa da revista $V_{e j a}$, de 16 de março de $2016^{1}$, bem como na reportagem principal no interior dessa revista, leva-nos a interessantes reflexões:

1 Edição 2469, ano 49, no 11. Imagem disponível em http://veja.abril.com.br/revistas. Acesso em 18/03/2016. 
Figura 1: Capa da revista Veja, de 16 de março de 2016

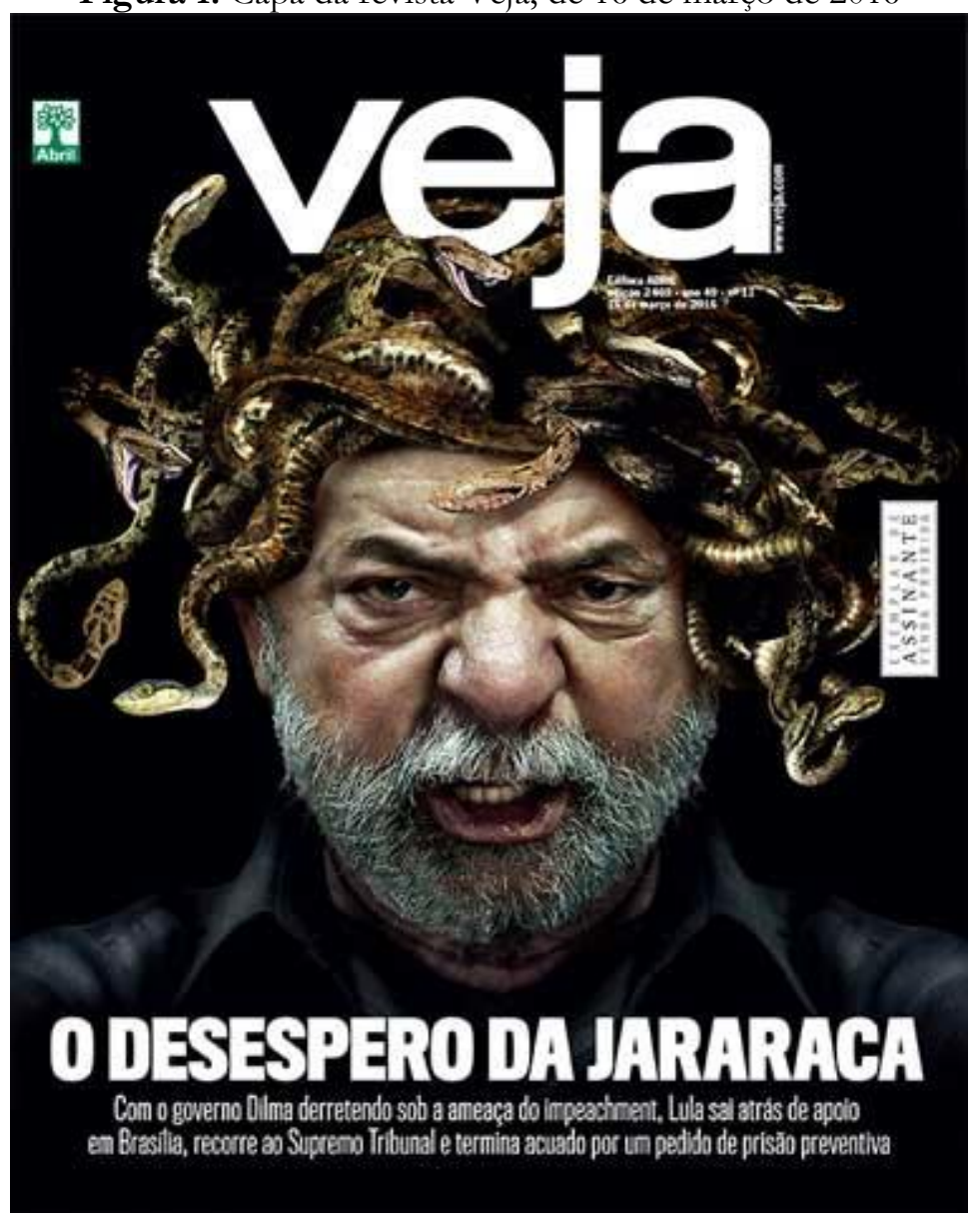

Courtine (2006, p. 66) afirma que o discurso político pode ser caracterizado como "o discurso que nasce a partir de uma fonte particular no interior do campo do discurso político", seja ele produzido por um enunciador dessa formação ou por uma fonte outra em um momento histórico relativo a determinada conjuntura política. Diante disso, consideramos aqui que o termo jararaca que aparece no enunciado "O desespero da jararaca", como manchete da capa de Veja, edição de 16/03/2016, como ilustrada acima, funciona discursivamente como uma resposta ao enunciado que é objeto de nossa reflexão neste artigo. Parte de uma mesma "conjuntura política" (ibidem), o enunciado "O desespero da jararaca" se apresenta em uma relação complexa de constituição da memória sobre o tenso momento do cenário político brasileiro do mês de março de 2016, como revela o lide da manchete: Com o governo Dilma derretendo sob a ameaça do impeachment, Lula sai atrás de apoio em Brasilia, recorre ao Supremo Tribunal e termina acuado por um pedido de prisão preventiva.

Ainda para Courtine "toda enunciação política é parte de um corpus de doutrina. E o que caracteriza tal conjunto de enunciados é que ele se apóia sobre 
uma tradição discursiva, um reagrupamento de coisas que foram ditas, que permite apenas o retorno ou retomada dos enunciados" (COURTINE, 2006, p. 66). Essa colocação de Courtine explica também o "retorno" do enunciado "Se quiseram matar a jararaca..." sob a forma da imagem que aparece na capa de Veja, acima, em uma multissemiose própria a esse gênero discursivo. Contudo, vemos aí a retomada do enunciado, mas reconfigurado no interior de outra formação discursiva, justamente aquela da oposição à trindade Lula/Dilma/PT. Vemos a imagem do expresidente Lula surgindo da escuridão, trajando preto e com feições raivosas, transformado não apenas numa jararaca, mas na rainha mitológica de todas as serpentes. Esse mecanismo de transformação Lula-Medusa não só retoma o enunciado de 04/03, filiando-o à outra formação discursiva, mas produz outro efeito de sentido. Por essa formação discursiva jararaca não quer significar "renovação de forças" e "convite à luta" pela sobrevivência política de Lula/Dilma/PT, mas justamente o contrário, com o sentido de colocar o expresidente Lula como uma fera maligna que, como no mito da Medusa, seduz, enfeitiça e petrifica/aliena todos que o (ad)miram.

\section{O DESLIZAMENTO DE SENTIDO: O OFIDIÁRIO}

Courtine (2006, p. 82) destaca o papel da memória no jogo de operações que torna possível a constituição e a dispersão do discurso político: "se o interdiscurso, portanto, organiza a recorrência e o reagrupamento de formulações, igualmente intervém como uma cavidade, ruptura ou deslocamento". Ainda, continua ele (idem), a memória se faz também de esquecimentos porque o interdiscurso "é o produtor do esquecimento dos enunciados. Memória e esquecimento não podem ser dissociados no modo de enunciação do discurso político". Por outro lado, como lembra Orlandi (2014, p. 58) "um acontecimento não para de produzir sentidos". Por causa disso, isto é, pelo jogo complexo da relação entre a memória e o acontecimento, o enunciado Se quiseram matar a jararaca... aparece reconfigurado por um deslizamento de sentido no interior da revista Veja de que aqui tratamos, na reportagem intitulada "A serpente acuada", matéria a que faz alusão a capa acima ilustrada.

"Embora a jararaca seja uma serpente endêmica da América do Sul, nenhum outro país do continente além do Brasil tem uma jararaca como Luiz Inácio Lula da Silva". É assim que começa a reportagem do jornalista Daniel Pereira, que ocupa as páginas 38 a 41 da revista Veja de 16/03/2016. Depois do título "A serpente acuada", vemos como foto principal que ilustra a reportagem a imagem do expresidente Lula ao lado do então presidente do Senado, Renan Calheiros. Ambos trajando preto, a cor dos trajes se mistura com a cor preta das duas páginas iniciais da reportagem que, quando abertas, dão a impressão de antigo álbum de fotografia, com retratos de pessoas que já morreram. À esquerda, Renan Calheiros olha de lado para o ex-presidente Lula. Com a mão direita espalmada sobre o coração, o semblante de Lula parece o de alguém prestes a ter um ataque cardíaco. As feições de dor e morte no rosto do ex-presidente ficam ainda mais bizarras quando observamos a imagem pouco nítida de uma mulher cuja figura delineia-se, mais alta 
que ele, na sua retaguarda. Trajando terno de cor vinho, cabelos com longas mechas loiras, a sombra da mulher parece a morte a espreitar o seu escolhido.

Como legenda da fotografia acima descrita, a palavra MITO, escrita em letras brancas sobre o braço direito, curvado, do ex-presidente Lula, e a inscrição "Lula com Renan Calheiros: busca de apoio para manter o que ainda lhe resta de poder e influência". No texto da reportagem, contudo, não há nenhuma outra referência explícita à palavra mito, o que permite chegarmos à conclusão de que os sentidos produzidos pelas imagens em conjunto, da capa da revista e das duas páginas iniciais da reportagem, podem ser parafraseadas da seguinte forma:

a) Lula $\Longleftrightarrow$ mito

b) $\mathrm{O}$ mito Lula $\Longleftrightarrow$ uma medusa raivosa, que ameaça

c) A serpente Lula-Medusa está acuada

d) O mito Lula está à beira da morte

Se, de um lado, não há nenhuma outra ocorrência do termo mito, com já o dissemos, o que deixa o sentido desse termo a ser (re)constituído pelo leitor com a cotação das imagens da capa da revista e da abertura da reportagem, por outro lado são muitas as ocorrências do termo jararaca ou equivalente. Esse é o caso, por exemplo, quando o articulista transcreve, na reportagem, um trecho da homilia do então bispo auxiliar da Arquidiocese de Aparecida, D. Darci José Nicioli, para ilustrar que, argumenta o articulista, até mesmo a CNBB, de histórica tradição de apoio ao PT, agora se volta contra o lulismo. A homilia teria sido proferida no domingo imediato ao quatro de março, "dois dias depois da bazófia", nas palavras de Daniel Pereira. "É hora de voltar à casa do pai. Pisar a cabeça da serpente. De todas as serpentes. Anular a força do mal e vencer o mal pelo bem. Coragem”, teria dito o bispo. A homilia foi proferida, segundo a reportagem, como uma reprimenda ao enunciado de que aqui tratamos e como uma benção ao trabalho de combate à corrupção. Serpente, pisar a cabeça, anular a força do mal, vencer o mal com o bem são termos que fazem alusão ao enunciado Se quiseram matar a jararaca..., mas o sentido desliza da/para a outra formação discursiva, a da "Fora Dilma!". A reportagem termina com mais uma alusão ao enunciado, com o mesmo deslizamento de sentido: "É desse veneno ofídico [Lula/Dilma/PT] que o Brasil precisa escapar para retomar o caminho das nações estáveis, prósperas e ao menos um pouco otimistas com o próprio futuro" (grifos nossos).

O que estamos chamando, neste ensaio, de deslizamento de sentido refere-se ao fato de os termos jararaca, ofídico, ofidiário, serpente, cobra, etc. serem enunciados e provocarem efeitos de sentido contrários ao pretendido pelo enunciado Se quiseram matar a jararaca não bateram na cabę̧a, acertaram o rabo. E a jararaca está viva como nunca esteve, do ex-presidente Lula. Ou seja, a referência à jararaca não produz mais o sentido de "sobrevivência", "luta" etc., mas o de "venenoso", "pérfido", "origem do mal", como se o sentido deslizasse de uma a outra formação discursiva. O mais emblemático desse deslizamento, contudo, aparece ilustrado na reportagem sob o sugestivo título de "O ofidiário de Lula", quadro à página 41 da revista, paralelo e complementar ao texto verbal da reportagem, em que aparecem fotos de "companheiros" do ex-presidente Lula, recognominados pelo articulista "cobras criadas do ex-presidente", a quem caberiam "a defesa incondicional do chefe e o ataque implacável de seus inimigos", conforme resumimos a seguir: 
- Paulo Okamoto. Jararaca-verde (presidente do Instituto Lula, ele é o guardião e administrador das "verdinhas" da família Lula da Silva);

- Jaques Wagner. Jararaca-da-praia (ministro de Dilma, o sempre bronzeado ex-governador da Bahia é o negociador de Lula por excelência);

- Renan Calheiros. Jararaca-do-cerrado (o atual presidente do Senado está ligado ao ex-presidente Lula por um pacto de sangue em meio ao cerrado da capital federal);

- Ricardo Berzoini. Jararaca-pintada (ex-sindicalista, ex-presidente do PT e agora ministro de Dilma, está sempre pintado para a guerra);

- Gilberto Carvalho. Jararaca-do-campo (o melhor amigo do MST é, para Lula, o perfeito pau para toda obra);

- Rui Falcão. Jararaca-de-barriga-vermelha (atual presidente do PT, sua missão é garantir que a sigla de bandeira vermelha e da estrela branca trabalhe a serviço do interesse do chefe).

Segundo Orlandi (2014), frente a um texto dado a ler como um acontecimento, a memória discursiva funciona a reestabelecer os implícitos, isto é, os pré-construídos "ausentes por sua presença" (p. 63), que sustentariam a interpretação. Ainda segundo essa autora (idem), a memória discursiva teria um papel singular na leitura/interpretação de uma imagem porque esta, como qualquer outro material semiótico, não é transparente. Materialidade significante, a imagem "tem seu funcionamento. Interpreta-se" (ORLANDI, 2014, p. 63). No que se refere às imagens aqui analisadas, podemos também compreender como deslizamento de sentido o preenchimento desses desvãos, das lacunas, dos implícitos deixados pelas imagens da capa e da reportagem principal da revista Veja, de 16/03/2016, como descrevemos nesta seção. Portanto, tal como afirmou Orlandi (idem), percebemos que o enunciado Se quiseram matar a jararaca... se faz presente na materialidade dos textos e imagens da capa e da reportagem de Daniel Pereira como uma ausência-presença necessária a amarrar os fios da memória discursiva, esquecimentos que consubstanciam esse acontecimento verbal, político e midiático.

\section{E, PARA CONCLUIR...}

O enunciado Se quiseram matar a jararaca não bateram na cabeça, acertaram o rabo. E a jararaca está viva como nunca esteve, proferido pelo ex-presidente Lula no dia 04 de março funcionou como um grito de guerra, como o som do apito que iniciou o jogo, embate político, jurídico e midiático que tencionou o Brasil durante todo o mês de março de 2016. Foram muitas as jogadas posteriores, que mereceriam melhor análise, mas que não foram objeto de reflexão neste ensaio. Posicionados os jogadores/combatentes, o enunciado, acontecimento verbal, político e midiático, fez ecoar o som estridente das tantas enunciações do "Não vai ter golpe!" e, consequentemente, do "Fora Dilma!", gritados nas ruas pelos manifestantes trajados de vermelho ou de verde-amarelo, no Parlamento, nos noticiários da televisão, nos debates do Supremo Tribunal Federal e, como aqui analisamos, na 
capa e na reportagem principal da revista Veja e de outras revistas semanais de informação.

Contudo, percebemos que se tratava mesmo e tão somente de GRITOS porque o que estava em jogo não eram necessariamente ideias, conceitos ou sugestões contundentes de como melhorar o Brasil. O que estava em jogo não era um embate sério de doutrinas políticas, mas apenas de partidos. Não havia doutrina. Ecoaram somente o "Não vai ter golpe!" ou o "Fora Dilma!", que, utilizando-nos da metáfora de Pêcheux (2002), funcionaram como o grito dos torcedores dos times de futebol, pró ou contra o governo da então presidente Dilma Rousseff e a liderança política do ex-presidente Lula. Não seria isso pelo fato de que são muitos os partidos e políticos igualmente enredados nos processos da Operação Lava Jato? São muitas as jararacas, portanto, infelizmente, vivas!

\section{REFERÊNCIAS}

COURTINE, Jean-Jacques. Metamorfoses do discurso político: derivas da fala pública. Trad. Nilton Milanez, Carlos Piovezani Filho. São Carlos: Claraluz, 2006.

ORLANDI, Eni Puccinelli. Discurso em análise: sujeito, sentido, ideologia. Campinas: Pontes, 2014.

PECCHEUX, Michel. O discurso: estrutura ou acontecimento. Trad. Eni Puccinelli Orlandi. 3. ed. Campinas: Pontes, 2002.

PEREIRA, D. A serpente acuada. Veja, São Paulo, edição 2469, ano 49, n 11, p. 38-41, 16 de março de 2016. 